Title:

ECONOMIC VALUE OF GLOBAL WEATHER MEASUREMENTS

Author(s):

Submitted to:
Gregory H. Canavan, P-DO

Jean E. Butterworth, P-DO
RECEIVED

MAY O 31999

OSTI

For discussions outside the Laboratory

MASTER

Date: 19 February 1999
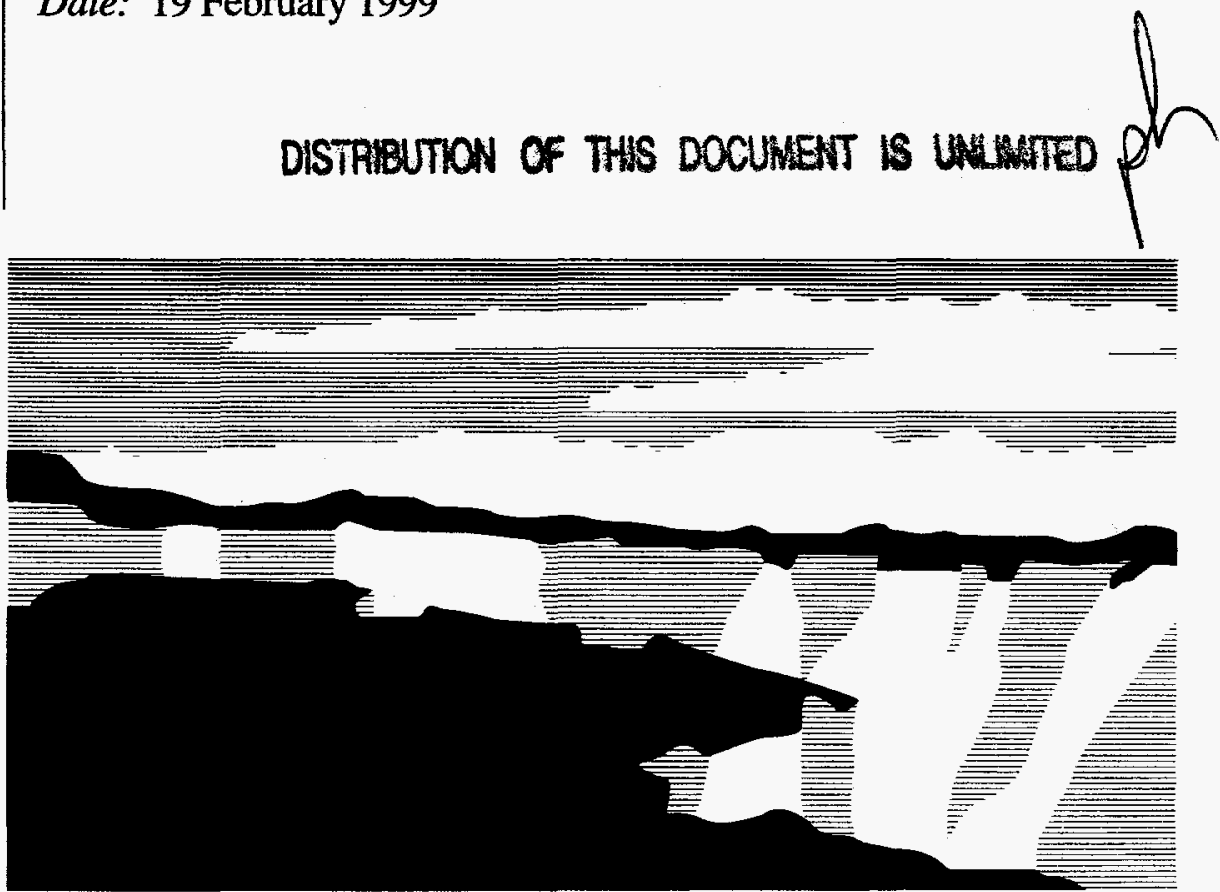

Los Alamos National Laboratory, an affirmative action/equal opportunity employer, is operated by the University of California for the U.S. Department of Energy under contract W-7405-ENG-36. By acceptance of this article, the publisher recognizes that the U.S. Government retains a nonexclusive, royalty-free license to publish or reproduce the published form of this contribution, or to allow others to do so, for U.S. Government purposes. The Los Alamos National Laboratory requests that the publisher identify this article as work performed under the auspices of the U.S. Department of Energy. 


\section{DISCLAIMER}

This report was prepared as an account of work sponsored by an agency of the United States Government. Neither the United States Government nor any agency thereof, nor any of their employees, make any warranty, express or implied, or assumes any legal liability or responsibility for the accuracy, completeness, or usefulness of any information, apparatus, product, or process disclosed, or represents that its use would not infringe privately owned rights. Reference herein to any specific commercial product, process, or service by trade name, trademark, manufacturer, or otherwise does not necessarily constitute or imply its endorsement, recommendation, or favoring by the United States Government or any agency thereof. The views and opinions of authors expressed herein do not necessarily state or reflect those of the United States Government or any agency thereof. 


\section{DISCLAIMER}

Portions of this document may be illegible in electronic image products. Images are produced from the best available original document. 


\title{
ECONOMIC VALUE OF GLOBAL WEATHER MEASUREMENTS
}

\author{
G. Canavan and J. Butterworth
}

\begin{abstract}
Global sensor networks could support increased activity in a number of economic sectors. Potential benefits and the predicted time scales required to realize them are estimated. Benefits are particularly compelling for fundamental reasons for aviation, hotels and restaurants, natural disasters, construction, agriculture, and apparel. These benefits can be captured by simple logistic approximations.
\end{abstract}

Large constellations of small balloons or satellites for meteorological observations could support global economic applications ranging from transportation to agriculture. The main requirement is timely revisit by quality sensors with rapid readout and dissemination of data. Global weather constellation could provide such measurements through rapidly evolving sensor and communication technology, which are described in companion papers. ${ }^{1}$ This note concentrates on their potential impact on the various sectors of the U.S. and global economies.

Over the last decade, U.S. government sponsored National Center for Advanced Technologies workshops have bounded the potential of remote sensing from space. They covered requirements for government, civil, and commercial players and programs; ${ }^{2}$ sensors, costs, and revenues. ${ }^{3}$ While concentrating on the benefits for agriculture, ecology, the environment, land use, and forestry, they gave guidance on impacts on other sectors as well.

Economic sectors. The U.S. domestic economy is summarized quarterly by the Bureau of Economic Analysis as shown in the attached Table, ${ }^{4}$ which shows the major components of the $\sim \$ 7 \mathrm{~T} / \mathrm{yr}$ gross domestic product (GDP). It is divided about 10/30/60\% between durable goods, non-durable goods, and services, of which the latter two are most susceptible to weather interruption. The Table divides activities into about 30 primary sectors, whose weather sensitivity is more readily apparent, using as a criterian the estimates of the benefits of improved predictions discussed below. The average value per sector is about $\$ 7 \mathrm{~T} / \mathrm{yr} / 30$ sectors $\approx \$ 230 \mathrm{~B} / \mathrm{yr}$, the average impact is $\approx \$ 7 \mathrm{~B} / \mathrm{yr}$.

This paper estimates the potential impacts of improved weather forecasts on these sectors at this level of aggregation. Little concrete prior analysis is available as a guide, so the process used has four steps. The first is to estimate the extent to which improved forecasts could increase the contribution from a given sector. The second is to estimate the time scale over which the forecast would have to remain accurate to produce that benefit. The third is to combine these parameters into an estimate of the benefits of improved predictions to each sector. The fourth is to combine these sector estimates into an overall estimate for the whole GDP.

There are uncertainties at each step. The estimates of percentage benefits per sector can at best be plausibility arguments. The estimates of sector time scales are essentially phase space 
estimates of the extent to which adverse weather currently impedes activity in those sectors. The combination of these two factors with the standard logistics curves used is plausible, but not unique. And the aggregation of sector benefits into an overall benefit to GDP could omit significant synergies. The paper compensates for these uncertainties by studying the sensitivity of its main results to each approximation.

Procedure. The basis for the assessment is the extent to which economic activity is impeded by unexpected adverse weather. That groups the economic sectors into three classes: major, intermediate, and modest impact. As a percentage of sector activity, the greatest benefits are predicted for fundamental reasons to be in aviation, hotels and restaurants, natural disasters, construction, agriculture, and apparel. Environment, transportation, trade, real estate, and insurance show lesser benefits. Remaining sectors show only indirect effects. Ranking sectors by time scales groups natural disasters, aviation, agriculture, textiles, and entertainment and recreation at the shortest time scales; a number of moderately sensitive sectors in the middle; and construction, home furnishing, environment, publishing, and apparel as requiring the longest forecasts.

These contributions to GDP, percentage potential benefits, and time scales can be summed over sectors to give the predicted benefits of any given prediction time, which can be approximated closely by a two-parameter logistic curve. Expected benefits increase linearly to $\sim \$ 110,160$, and $180 \mathrm{~B} / \mathrm{yr}$ for prediction times of one, two, and three weeks, which are thought to be attainable. Four to six week forecasts may be possible, but are not essential on the basis of these estimates. The overall predicted benefits of $\$ 100-200 \mathrm{~B} / \mathrm{yr}$ are $\sim 1-2 \%$ of the GDP, which is consistent with a cursory inspection of the sensitivity of overall economic activity to weather disruptions.

U.S. GDP values are used, but a long-range forecasting system is intrinsically global, both in its need to collect data globally and in its ability to disseminate that data to all nations in near real time. Thus, it is intrinsically an international system, and its benefits should be estimated accordingly. That is done only roughly here. The benefit to the U.S. of improved longrange weather forecasts is estimated below to be on the order of $\$ 100 \mathrm{~B} / \mathrm{yr}$. The U.S. GNP is roughly a third of the combined output of the developed economies; thus, its global impact could be on the order of $\$ 300 \mathrm{~B} / \mathrm{yr}$, which would be more than adequate to justify international development and exploitation.

Economic impact. The basis for the assessment of impact used here is the extent to which economic activity is directly impeded by unexpected adverse weather. This criteria groups the economic sectors into three rough classes with major, intermediate, and modest impact, whose percentage benefits are shown in Fig. 1 . 
Aviation. The direct cost of fuel and the capital cost of properly positioning aircraft for the successive day's operations are significant costs for commercial aviation. Better measurement of winds aloft would minimize fuel costs, and longer predictions of weather would permit basing aircraft and crews closer to where they are needed for the subsequent flight. Avoiding a 60 knot headwind on a cross-country flight could reduce flying time $10 \%$, and fuel costs even more. Optimally rerouting around local disturbances could produce savings $\sim 10 \%$. In addition, distributed weather transponders would provide a direct local measurement of local shear and turbulence, which could provide a comparable benefit in the form of improved safety. Moreover, their transmissions could be received and interpreted directly by the aircraft, which would minimize impact probability as well as provide valuable local planning information to aircraft in flight. The overall fuel, efficiency, and safety contributions could sum to roughly $15 \%$, as shown on Fig. 1.

Hotels and Restaurants are discretionary activities, which can be delayed in case of adverse weather. That is especially so for vacation and resort activities, which are totally dependent on weather-witness the current lack of snow pack in major ski areas. Improved forecasts would improve the consumer's ability to plan outings and retailers' ability to provide the supplies needed to support them. The two effects are both positive and appear to be of similar magnitudes. As vacations are planned weeks to months ahead, prediction times on that order could reduce discretionary costs, including secondary impacts on transportation, by tens of percent. A week's prediction could provide similar cost reductions for local restaurants and entertainment. Summing these effects gives a total impact on the order of the $14 \%$ shown. The slight reduction from the benefit from aviation is intended to indicate that the reductions are less likely to dominate this sector, not to imply $10 \%$ precision in the estimates.

Natural Disasters cost about $\$ 120 \mathrm{~B}$ in 1998 and averaged about half that over the past decade. Much of this damage and loss of life could have been avoided, had accurate predictions of the extent of winter storms, the landing points of hurricanes, and the boundary conditions for fires been available. While some loss is unavoidable, enough time for preparation or evacuation could have avoided much of the loss of property and most of the loss of life. The $13 \%$ shown is a conservative figure based on the limited data due to the generally inadequate warning to date.

Construction is a major sector of the economy. While some components such as office and industrial construction is largely insensitive to weather, other parts such as residential and commercial construction are largely carried out in good weather. The impact on them of unforeseen adverse weather is three-fold: the direct financial cost to the builder due to delays, the lost wages to workers, and the delay of occupancy by buyers. Each is significant. For example, if a three month project was interrupted for two weeks, the builder's construction cost would increase $\sim 2 / 12$ weeks $\sim 17 \%$; the workers would loose $\sim 20 \%$ of their wages, and the buyer 
would have to pay a similar amount for interim facilities, so the total cost of the project would increase $\sim 20 \%$. Since major storm fronts take on the order of a week to pass, and do so on the order of each month during the building season, the $12 \%$ estimate shown is probably conservative.

Agriculture. Fertilizer, irrigation, harvesting equipment, transportation, and storage are major costs of food production, and timing is the essence of getting it to market in a prompt and economical way. Improved forecasts could improve each. With longer range forecasts, it would be possible to fertilize where needed and irrigate when needed. That would minimize the equipment, transportation, and storage needed for interim and final disposal. Two to four week predictions of weather and precipitation should make it possible to optimize the combination of input factors and harvest time to maximize production and profits. As the harvest interval at any given latitude is on the order of a few weeks, and adverse weather during harvest can be catastrophic, the potential savings are tens of percent. However, the times that detailed forecasts are needed are a fraction of that total, so the overall benefit is reduced to the $\sim 10 \%$ shown, which is in accord with independent estimates. ${ }^{5}$

Apparel purchases are extremely weather elastic, witness the current racks of winter clothing and ski parkas marked down $50 \%$ or more. While avoiding all of these commercial losses would require 2-3 month predictions, 2-4 week predictions could minimize the costs of overproduction, transportation, and advertising. Such predictions would reduce the producer's cost through more timely purchasing and advertising and the consumer's cost through better informed preparation for the next season or year through sale shopping. While the benefits in the components above are extremely large, the overall impact is reduced to the $10 \%$ shown.

Entertainment and Recreation, like hotels and vacations, are largely discretionary activities, which can be delayed or cancelled for adverse weather. Thus, improved predictions should make possible improved planning of activities and support, with an indirect impact on transportation and energy requirements. Improved forecasts would improve the consumer's ability to plan outings and the retailer's ability to provide supplies. As entertainment is generally planned a few days to a week in advance, prediction times on that order could reduce costs by tens of percent. The total impact could be on the order of 6-10\%.

Environment. Measuring the environment and assuring compliance with environmental regulations is a significant cost today; it will increase $\sim 10$-fold to $\sim \$ 1 \mathrm{~B} / \mathrm{yr}$ or more under proposed regulations. If global warming is confirmed, it is likely to increase even further. For such measurements to be useful and credible, they must be objective and global, which is a unique and powerful advantage of the proposed global transponder system. Calibrated, objective measurements of meteorological variables could both support pollutant dispersal calculations and measure their accuracy. Such measurements could magnify the impact of other measurements. 
They could be essential to gaining support. Thus, the $6 \%$ benefit indicated is a conservative estimate of the benefit of these measurements for any level of environmental measurements.

Transportation is significant for both commercial and recreational purposes and for car, rail, sea, and air carriers, as discussed above. Commuters primarily rely on cars. During some day to week-long periods in the winter, car transportation is not possible, so work is delayed and wages are lost. With adequate day-to-week forecasts, those transportation losses could be eliminated and those lost days converted into productive time using the internet home-office technologies that are now developing rapidly. During the harvest season, it is now necessary to pre-position railroad cars in anticipation of good weather and early harvests. Improved forecasts could improve pre-positioning and maximize the use of rolling stock. Sea transport would benefit from fuel savings from more efficient route planning with 1-2 week forecasts, which could lead to a direct fuel, crew, and capital savings of $\sim 5 \%$, leading to the composite estimate shown.

Trade has two dimensions, domestic and international. The ability to use forecasts to eliminate overproduction and target advertising to times of consumer availability is discussed above. Consumers shop during good weather; shopping is reduced during periods of rain or snow. Improved forecasts would permit consumers to plan their shopping and allow retailers to optimally schedule resupply. That is true both domestically and internationally. With $2-4$ week forecasts, global shopping and resupply requirements could be met more efficiently and shifted awar from periods of slack demand, which would result in savings of several percent.

Real Estate. Commercial and private real estate are primarily constructed during periods of good weather. Thus, the cost to each is directly proportional to the fraction of unanticipated adverse weather. Some of those costs-particularly the dominant labor costs-could be largely eliminated with 2-4 week forecasts, which would make it possible to shift workers from impacted areas to other regions with acceptable weather. A second dimension is sales. It is difficult to sell a house in a severe snow storm, unpleasant to buy one in an extended rainy warm front. Longer range forecasts would make it possible for sellers, buyers, and realtors to schedule their activities and travel to take better advantage of the best weather for each activity, which is assumed to lead to the benefit shown.

Intermediate impact sectors have significant sensitivity to weather, but it is more difficult to document due to the indirect interaction involved.

Insurance is a major industry in the U.S. and globally. Virtually all cargoes, carriers, crews, repositories, and deliveries are fully insured. Thus, life, property, and casualty rates and volume are all driven by weather-related incidents. Better forecasts could improve trip and transport planning, which could reduce accidents, losses, and rates. Air and maritime travel are important examples. Maritime voyages typically last several weeks; thus, improved forecasts could both permit improved route planning and minimize the probability of catastrophic loss in 
storms. This improvement would be reflected throughout the investment sector that derives from this insurance underwriting activity. If a typical transport takes a week, and weather delays could cause a delay of a day, that would cause a loss of $\sim 10 \%$. Such delays occur about $10 \%$ of the time. Together with catastrophic losses of $\sim 1 \%$, that giving the $\sim 3 \%$ shown on Fig. 1 .

Building Materials production is sensitive to conditions at the material source, which under adverse conditions may be impassable; thus, it is highly weather dependent. With adequate forecasts, it should be possible to schedule production from sites with adequate weather and shift workers to those sites. That is not practical with current predictions, but several weeks notice should make it possible to optimize site and delay workers to largely eliminate weather delays. As those delays currently occur for a week out of a few months, those benefits could be on the order of $\sim 5-10 \%$. Thus, the $2 \%$ shown is conservative.

Energy demand varies inversely with temperature on a daily, weekly, monthly, and seasonal basis. Improved forecasts would permit more efficient wheeling and peaking for daily loads, sharing arrangements for weekly distribution, and storage for monthly and seasonal anomalies. The ability to wheel and peak efficiently directly impacts capital costs, which are the dominant elements of the price of power. Sharing arrangements determine transmission investment, and orderly storage could stabilize the swings in prices due to arbitrage, which make orderly planning for unexpected phenomena such as the unexpected January freeze over the U.S. Better forecasts for conventional sources would also directly impact the demand for and development of alternate sources of energy, as well as that for environmental controls and pollution abatement. Impacts vary widely. Replacing peak capacity with transmission from unaffected regions would reduce costs directly. Capital costs are $\sim 30 \%$ of total; thus, transmission for 3 days of each month could save $\sim 10 \%$. Fuel oil is stored at a carrying charge of $\sim 10 \%$, so eliminating disruptions such as the two month glut experienced in the U.S. in the fall of 1998 would save $\sim 20 \%$. The $2 \%$ shown assumes that recent weather patterns are anomalous.

Food Processing (agriculture and ranching) is strongly inhibited by adverse weather-the former because crops are inaccessible or ruined; the latter because livestock are killed or immobilized. Improved predictions should permit more efficient scheduling of crop maturation, harvesting. It should also reduce costs for transportation, processing, and storage facilities, which are a significant fraction of the cost of the finished product. Better forecasts could also eliminate supply bottlenecks and permit more efficient planning.

In agriculture, the direct benefit of saving crops that would be destroyed by adverse weather is discussed above. The costs of transportation, processing, and storage are comparable. Reducing peak capacity by scheduling separate areas could be done with predictions of 1-2 weeks, the time for transshipment. The same could be done with livestock with the 2-3 week 
warning needed for transport, feeding, and processing. Since the duration of peak activity in each are measured in weeks to months, 1-3 week predictions could save $20-30 \%$ of the losses. If such losses were experienced by $\sim 20 \%$ of separate geographic areas on the average, this would lead to $\sim 4-5 \%$ benefits, which are understated by the $2 \%$ shown.

Mining is impacted by the accessibility of open pit sites, which are an increasing fraction of both energy and mineral extraction. With 3-7 day predictions, effort and crews could profitably be shifted to accessible sites, which would save about $\sim 10 \%$. Assuming that would impact $\sim 20 \%$ of the sites leads to the $2 \%$ estimate shown.

Paper and Forest products production is directly impacted by the accessibility of the forests involved. While that would not be impacted by better forecasts, men and material could be better reallocated to alternative sites or tasks with few days to few weeks forecasts. The saving is directly proportional to the fraction of days otherwise be impacted, which would lead to savings of several percent. That is also the basis for oil field services for largely the same factors.

Telecommunications would be improved by better predictions of weather outages, particularly high-volume, high-margin wireless communication, which is increasing rapidly. Unexpected outages drive both parallel entry points and their capacity. These entry points are $\sim 10 \%$ of the cost of such systems, so eliminating duplication could save on the order of $5 \%$ in capital and a like amount in operating expenses.

As a by-product, the availability of global weather measurements could generate private, commercial, and governmental demand for the rapid distribution of the data. That could further increase the demand for telecommunications services-particularly in that the data taken over a given nation could be immediately processed locally for its benefit as well as fused with global data. Such data would improve global weather awareness, which could create a new economic dimension to the industry.

Modest impact sectors are largely those with centralized, indoor production facilities.

Auto \& truck manufacturing \& parts are generally at a few centralized sites. It is difficult to distribute the assembly, so it would be difficult to effectively shift work and people even with significant prediction time. However, the workers do have to reach their sites, which are largely in northern regions; thus, weather predictions of even days to weeks could avoid accidents and losses and enable workers to schedule travel, leading to the $1 \%$ estimate shown.

Industrial services are tied to the industries they service, so it is difficult to distribute them. Workers and products have to reach those sites, so days to weeks weather predictions could avoid accidents and losses to the $1 \%$ estimate shown.

Petroleum production is increasingly tied to large rigs in remote areas with adverse weather much of the time. Crews do have to be rotated safely and products must be removed efficiently. Both operations are strongly weather sensitive, with delays of days compromising the 
operation. Thus, day to week forecasts could save $\sim 0 \%$ on operations that are $\sim 10 \%$ of the entire enterprise, which leads to the $\sim 1 \%$ estimate shown.

Textiles are dependent on the harvest and transport of the raw materials. Thus, like agriculture generally, they are susceptible to both crop destruction and delays due to adverse weather. The harvest cycles are again days to weeks, to which the capital-intensive transport system is also sized. Predictions of a week could save crops and production over regions constituting $\sim 10 \%$ of the total, leading to the savings shown.

Banking and Finance savings result from more efficient underwriting of industrial and transportation activities, which is complementary to the insurance activities discussed above. If crops, production, and transport are more orderly and less risky, their financing can be more orderly and less expensive as well. Reducing disruptions $\sim 10 \%$ for the riskiest $\sim 10 \%$ of the portfolio would produce the $\sim 1 \%$ benefit shown.

Chemicals are largely produced in large, centralized facilities. Workers do have to reach them safely, and products must be exported efficiently-both of which are weather sensitive-so few day to week forecasts could save $\sim 10 \%$ on operations that are $\sim 10 \%$ of the enterprise, which leads to the $\sim 1 \%$ estimate.

Electrical \& electronic products are largely produced in large, centralized facilities, but workers have to reach them safely, and products must be shipped efficiently, which leads to an estimate of $a \sim 1 \%$ benefit.

Health care is provided in centralized facilities, but workers, patients, and injured persons have to reach them safely, which leads to a $\sim 1 \%$ estimate. A special issue is health care for remote areas, which could be scheduled much more efficiently with 1-2 week predictions.

Home furnishings \& appliances are largely produced in centralized facilities, but workers must reach them safely, and products must be shipped, which leads to an estimate of $a \sim 1 \%$ benefit. Moreover, home furnishings and appliances are closely tied to home purchases and construction, which are strongly weather dependent. Thus, improved forecasts, which could regularize home purchases and construction, would also make it possible to schedule home furnishing and appliance production more optimally, although that is an indirect interaction that is more difficult to quantify.

Investment activity is the basis of capital construction, production, transport, and much of consumption. As each of those activities is weather sensitive, so is investment activity. Although the direct impact on the volume of investment needed to support those activities is significant, the indirect effect of leveling out those flows could be as significant. Making use of the capital that undergirds these interactions more efficiently by $1 \%$ would reduce the cost of financing them by the like amount shown. 
Machinery and fabrication are largely in large, centralized facilities, but workers have to reach them safely, and products must be shipped efficiently, which leads to an estimate of a $\sim 1 \%$ benefit. Better estimates could also be used to level demand and production schedules.

Miscellaneous services is composed of a large number of sectors that are all sensitive to the need for workers to reach them safely and for their products to be shipped efficiently, leading to an overall estimate of $\mathrm{a} \sim 1 \%$ benefit.

Cumulative sector impact. Figure 2 shows the cumulative benefits as a function of economic sector in order of decreasing benefits. Cumulative benefits start at about $\$ 60 \mathrm{~B} / \mathrm{yr}$ from trade, increase rapidly through construction and real estate, then more slowly to $\$ 160 \mathrm{~B} / \mathrm{yr}$ by natural disasters and $\$ 200 \mathrm{~B} / \mathrm{yr}$ by environment. Subsequent differential sector contributions are smaller, leading to an asymptotic cumulative benefit of about $\$ 230 \mathrm{~B} / \mathrm{yr}$, not all of which could be realized.

Trade gives a differential and cumulative benefit of about $\$ 60 \mathrm{~B} / \mathrm{yr}$, which is about $1.1 \%$ of GDP. That is primarily because of its large contribution to GDP-its fractional impact from Fig. 1 is only about $5 \%$. The $\sim \$ 30 \mathrm{~B} / \mathrm{yr}$ contribution from construction is the product of a smaller contribution to GDP and a larger percent benefit. Real estate gives a contributions of $\sim \$ 30 \mathrm{~B} / \mathrm{yr}$ from a larger contribution to GDP and a smaller percentage. Agriculture and natural disasters have moderate contributions to GDP and significant percent benefits. Aviation has a modest contribution and a high percentage; transportation a high contribution and modest percentage; hotels and restaurants a modest contribution and high percentage. Other sectors have decreasing percentages, except for apparel, which has a $10 \%$ potential benefit, but only a $\$ 32 \mathrm{~B} / \mathrm{yr}$ contribution to GDP. These sectors typically have differential impacts $<0.1 \%$ of GDP.

About $\$ 150 / 230 \mathrm{~B} / \mathrm{yr} \sim 65 \%$ of the potential benefit comes from the first 4-5 sectors-trade, construction, real estate, aviation, and natural disasters. About $87 \%$ comes from the first 10 sectors-through environment. The combined contributions from the other 20 sectors is only $\sim 10 \%$. These percentages are, however, altered somewhat when their time scales are taken into account, as some sectors such as real estate and trade have 4-5 day scales, which are difficult to satisfy fully.

Characteristic time scale. The previous section gave some indication of the prediction time scales necessary to realize the benefits estimated there. Prediction time is the duration of accurate forecast required to realize about $50 \%$ of the maximum benefit possible from a given sector. Figure 3 summarizes those estimates for each sector. Natural disasters, aviation, agriculture, and textiles have the shortest characteristic times-3 to 5 days-in accord with the transient storms, wind, rain, and growth that govern them.

The next group-entertainment, health care, and food processing-are also strongly sensitive to weather, indirectly through consumer choices, timing, and resource scheduling. The 
group consisting of transportation through energy are sensitive to the direct impact of adverse weather on workers, transportation, and transshipment-as are telecommunications, services, electrical, auto, and machinery-on a slightly longer time scale. Insurance, finance, and investment are sensitive on the 1-2 week time scale of the shipments and interactions they finance and insure.

Trade, particularly international shipping, is sensitive on 2-3 week time scale of shipments. Real estate and services are sensitive on the planning time lines of customers. Hotels and restaurants are discretionary on even longer time scales. Construction and furnishing are jointly sensitive to weather on 3-4 week time scales if efficient reallocation of resources and workers is possible. Finally, environmental measurements, publishing, and apparel are sensitive on monthly to seasonal time scales.

Sector benefits from sector $i$ can be approximated by a logistic curve $B_{\mathrm{i}}=\mathrm{B}_{\mathrm{Mi}}\left(1-\mathrm{e}^{-t / \mathrm{i}}\right)$,

where $i$ is an index for the sector, $t_{i}$ is its characteristic time from Fig. 2, $B_{M i}$ is the maximum benefit possible from that sector, i.e., the product of the percentage benefit of Fig. 1 and the sector GDP contribution of the Table. Figure 4 shows the cumulative benefit, $\Sigma_{i t} B_{i}$, as a function of $\mathrm{t}_{\mathrm{i}}$. It rises linearly for benefits of 10 to $230 \mathrm{~B} / \mathrm{yr}$, but then turns almost vertical for larger values. That indicates the benefits to longer measurement and prediction times increase proportionally through 2-3 weeks, after which much greater increases in predictions are required to realize the smaller remaining benefits. This sharp increase in slope is due in part to the neglect of the benefits of long time scale resource, environmental, and climate measurements, which could be of great value, but have not yet been bounded. In any case, those time scales are too long to impact the 2-4 week weather forecast improvements of concern here.

Figure 5 shows the dollar benefits of the top ten sectors as function of prediction time. The top curve for trade reaches $\sim \$ 25 \mathrm{~B} / \mathrm{yr}$ in one week, $\$ 40 \mathrm{~B} / \mathrm{yr}$ in two, $\$ 48 \mathrm{~B} / \mathrm{yr}$ in three weeks, and continues to grow for all prediction times shown. The second curve for construction rises more rapidly but saturates at about $\$ 30 \mathrm{~B} / \mathrm{yr}$ after three weeks. The third curve for real estate increases more slowly, but continues to grow for all times. The other curves saturate in similar times at levels determined by the product of their contribution to GDP and percentage benefit.

Cumulative impact. Figure 6 compares the variation of benefits summed over all sectors as a function of prediction time to the approximate form

$$
B \approx B_{M}\left(1-e^{-t /<D}\right),
$$

where $\mathrm{B}=\Sigma \mathrm{B}_{\mathrm{i}}, \mathrm{B}_{\mathrm{M}}=\Sigma \mathrm{B}_{\mathrm{Mi}}$, and $\left\langle\mathrm{t}>\right.$ is an approximation to the weighted average of $\mathrm{t}_{\mathrm{i}}$ over sectors using the $\mathrm{B}_{\mathrm{Mi}}$ as weighting functions. The value of $\langle\mathrm{t}>$ used is 11 days, which gives $\sim 5 \%$ agreement overall, although it rises slightly too slowly for small $t$ and overshoots slightly at $t>4$ weeks, which is not of interest here. 
Computed and approximate benefits increase essentially linearly from 0 to $\sim \$ 110 \mathrm{~B} / \mathrm{yr}$ as the prediction time increases from 0 to 1 week. They then increase more slowly from $\sim \$ 110 \mathrm{~B} / \mathrm{yr}$ to $\$ 160 \mathrm{~B} / \mathrm{yr}$ as the prediction time increases from 1 to 2 weeks, and from $\sim \$ 160 \mathrm{~B} / \mathrm{yr}$ to $\$ 180 \mathrm{~B} / \mathrm{yr}$ as it increases from 2 to 3 weeks. Thereafter, they increase more slowly to $\sim \$ 220 \mathrm{~B} / \mathrm{yr}$ after 6 weeks. One week is less than a factor of two beyond current forecast times, so its significant benefit should be readily attainable. Two weeks is a current estimate for atmospheric predictability times, so the $\$ 160 \mathrm{~B} / \mathrm{yr}$ is arguably attainable. Three weeks may be possible, depending on decorrelation times that could be measured by the sensor net itself. Four to six week forecasts may be possible, but are not essential on the basis of the benefits indicated.

Summary and conclusions. Large constellations of small balloons or satellites for meteorological observations could support global economic applications ranging from transportation to agriculture. The main requirement is timely revisit by quality sensors and rapid readout and dissemination of data, which could be provided by the rapidly evolving technologies for miniaturized sensors and communication. This note describes their potential impact on the various sectors of the U.S. economy. The extension to global benefits can to first order be estimated by a ratio of developed geographic areas.

The basis for the assessment of impact is the extent to which economic activity is impeded by unexpected, adverse weather, which groups the economic sectors into classes with major, intermediate, and modest impact. As a percentage of sector activity, the greatest benefits are predicted to be in aviation because of its fuel, capital, and crew costs; hotels and restaurants because of customer discretion; natural disasters because of short time scales and mounting costs; construction because of its restriction to useful weather; agriculture because of the tight timing of harvests and processing; and apparel because of the strong seasonal dependence of sales. Environment, transportation, trade, real estate, and insurance show lesser benefits. Remaining sectors show moderate indirect dependences.

Ranking sectors by time scale gives a different ordering, with natural disasters, aviation, agriculture, textiles, and entertainment and recreation at the top; a large number of moderately sensitive sectors in the middle; and a few sectors such as construction, home furnishing, environment, publishing, and apparel requiring the longest forecasts.

These contributions to GDP, percentage potential benefits, and time scales can be combined with a set of logistic curves proportional to the product of GDP contribution and percentage benefit that saturate when the forecast duration is large compared to the time scale of the sector. Summing these curves over sectors then gives the predicted benefits of any given prediction time. The result can be approximated closely by a two-parameter logistic curve in which the first parameter is the total expected benefit and the second is a sector-average time scale of about 11 days. 
The expected benefits increase linearly to $\sim \$ 110 \mathrm{~B} / \mathrm{yr}$ for prediction times of one week; more slowly to $\$ 160 \mathrm{~B} / \mathrm{yr}$ for two weeks, and to $\$ 180 \mathrm{~B} / \mathrm{yr}$ for three weeks, all of which should be attainable. Four to six week forecasts may be possible, but are not essential on the basis of the cumulative benefits predicted. Overall benefits of $\$ 100-200 \mathrm{~B} / \mathrm{yr}$ are $\sim 1-2 \%$ of the GDP, which is reasonable on inspection of the sensitivity of overall economic activity to weather disruptions. 


\section{References.}

1. G. Canavan and L. Wood, "Distributed Remote Sensing from Constellations of Small Satellites," A. Zichichi Ed, International Seminar on Planetary Emergencies (London, World Scientific, 1991), pp. 277-81; Los Alamos Report LA-UR-91-2780, Sept 1991.

${ }^{2}$. R. Hartke, Minutes of the First Government/Industry Meeting on Remote Sensing (National Center for Advanced Technologies, 1250 Eye St., NW Suite 1100, Washington, DC 20005, 11 November 1992).

${ }^{3}$. R. Hartke, Minutes of the Second Government//hdustry Meeting on Remote Sensing (National Center for Advanced Technologies, 1250 Eye St., NW Suite 1100, Washington, DC 20005, 19 April 1993).

${ }^{4}$. Overview of the Economy (U.S. Govt, Bureau of Economic Analysis, July 1998).

${ }^{5}$. R. Hartke, Minutes of the Second Government/Industry Meeting on Remote Sensing, op. cit. 
Table. U.S. economy by sector.

\begin{tabular}{|c|c|c|c|}
\hline Sector & GDP & $\begin{array}{c}\% \% \\
\text { Benefit }\end{array}$ & $\begin{array}{c}\text { Time Scale } \\
\text { (days) }\end{array}$ \\
\hline \multicolumn{4}{|l|}{ Strong Impact } \\
\hline Agriculture & 149.6 & 10 & 14 \\
\hline Apparel & 32.5 & 10 & 14 \\
\hline Banking \& Finance & 191.9 & 5 & 28 \\
\hline Building Materials & 62.4 & 10 & 28 \\
\hline Construction & 274.4 & 20 & 14 \\
\hline Energy & 299.8 & 5 & 28 \\
\hline Entertainment/Recreation & 82.8 & 10 & 28 \\
\hline Environment & 100.0 & 5 & 14 \\
\hline Food Processing & 106.7 & 3 & 14 \\
\hline Hotels \& Restaurants & 56.8 & 20 & 14 \\
\hline Insurance & 136.6 & 5 & 14 \\
\hline Investment & 172.0 & 2 & 28 \\
\hline Natural Disasters & 100.0 & $\overline{30}$ & 14 \\
\hline Paper \& Forest Products & 48.9 & 4 & 14 \\
\hline Telecommunications & 197.9 & $\overline{3}$ & 14 \\
\hline Trade & 1245.5 & 5 & 14 \\
\hline Transportation & 169.7 & $\overline{3}$ & 14 \\
\hline Aviation & 72.6 & $\overline{20}$ & 14 \\
\hline \multicolumn{4}{|l|}{ Limited Impact } \\
\hline Auto \& Truck mfg; parts & 121.9 & 1 & $\overline{14}$ \\
\hline Chemicals & 152.0 & 2 & 14 \\
\hline Electrical/Electronics & 261.2 & 1 & 14 \\
\hline Government & 684.0 & 2 & 28 \\
\hline Health Care & $\overline{379.0}$ & 2 & 14 \\
\hline Home Furnishings; appl. & 19.7 & $\frac{2}{1}$ & 28 \\
\hline Industrial Services & 402.2 & 2 & 14 \\
\hline Machinery \& Fabrication & 367.6 & $\overline{2}$ & 14 \\
\hline Mining & 54.2 & $\overline{10}$ & 28 \\
\hline Misc. Services & 483.4 & 2 & 28 \\
\hline Petroleum Production & 86.1 & 3 & 14 \\
\hline Publishing & 76.7 & 1 & 28 \\
\hline Real Estate & 814.8 & 5 & 28 \\
\hline Textiles & 25.7 & 3 & 28 \\
\hline Adjustment of GDP & -1597 & & \\
\hline TOTAL & 7268.9 & 365.6 & \\
\hline & & & \\
\hline
\end{tabular}




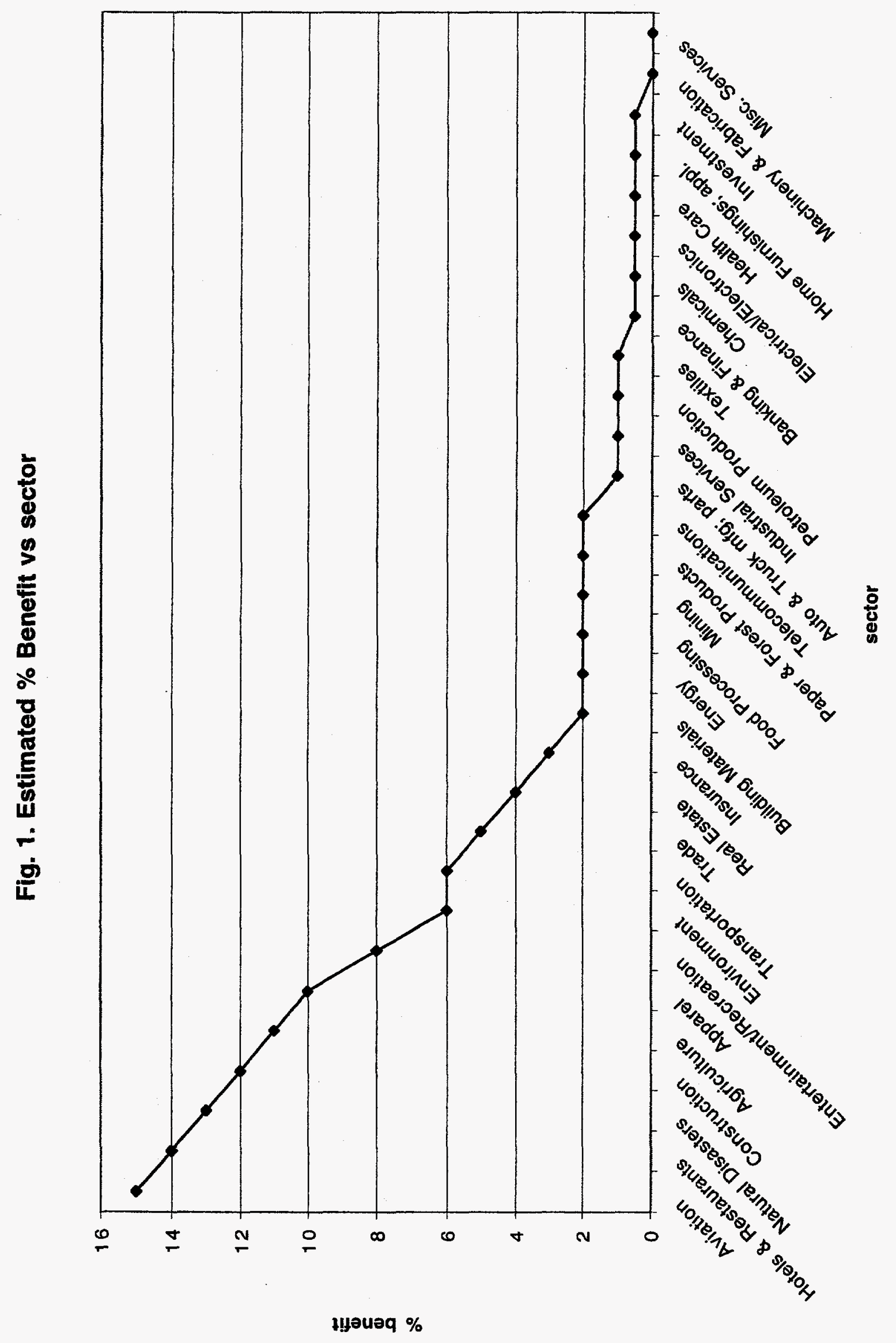




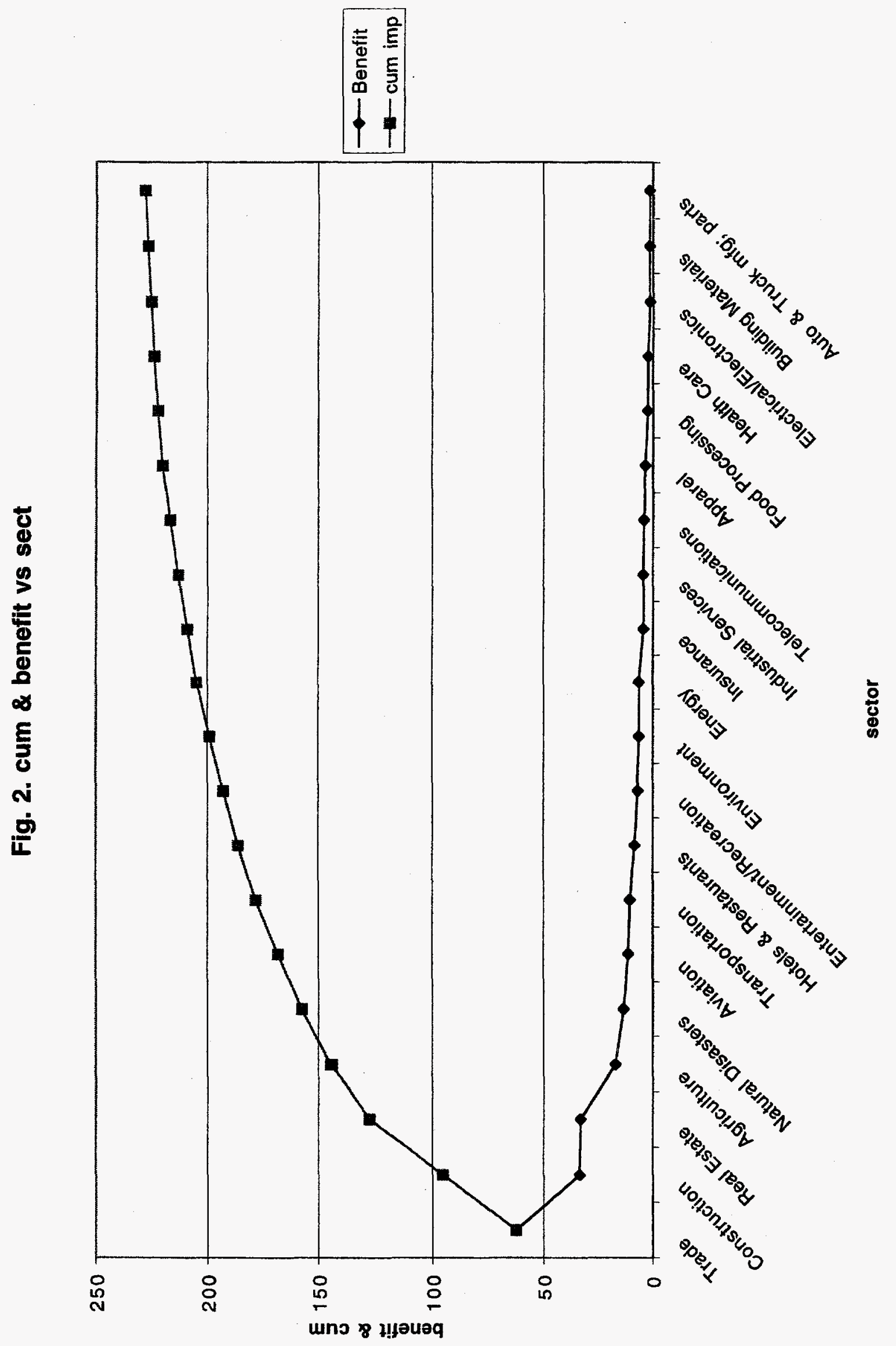




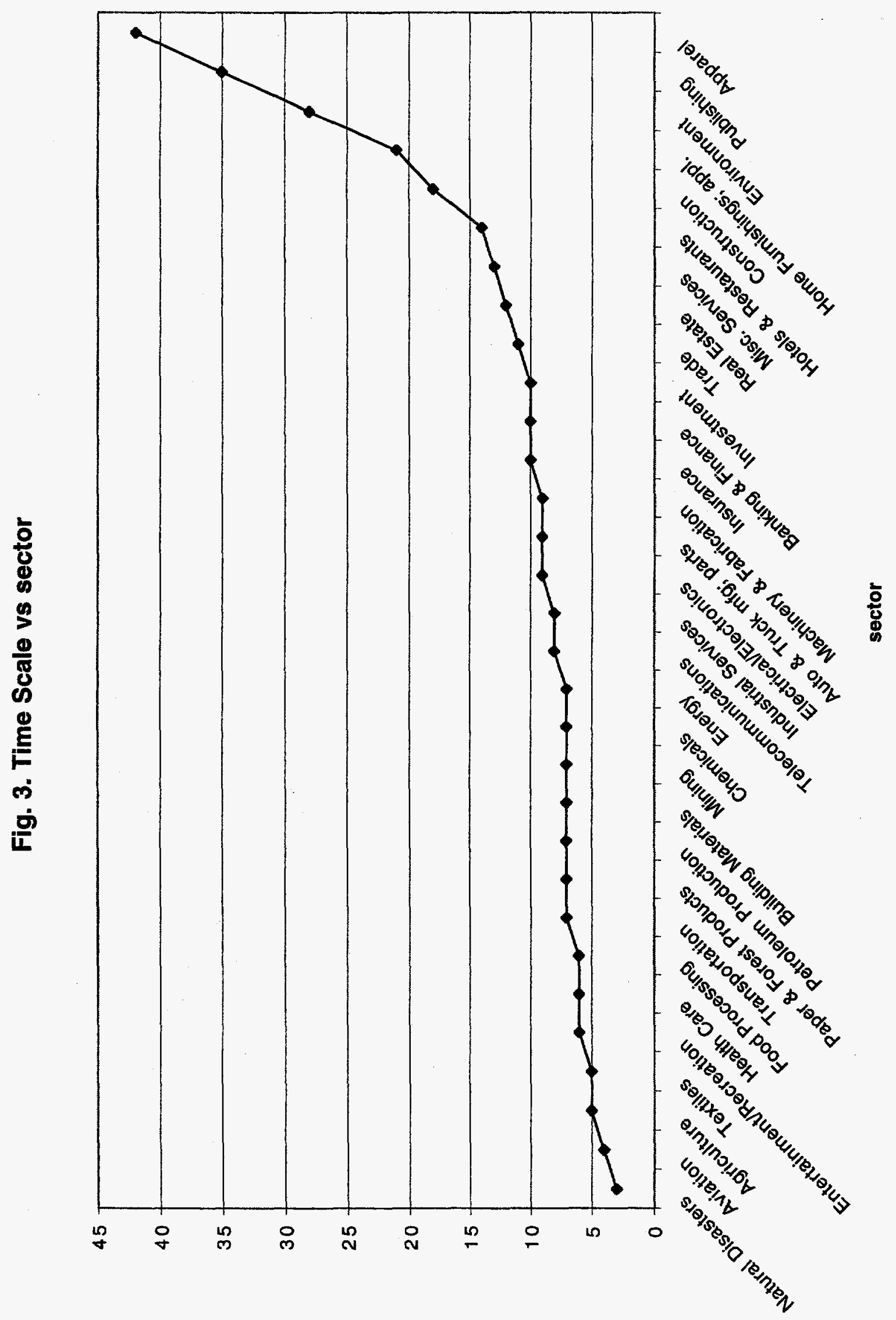

(sאep) ә|еวs әu!! 


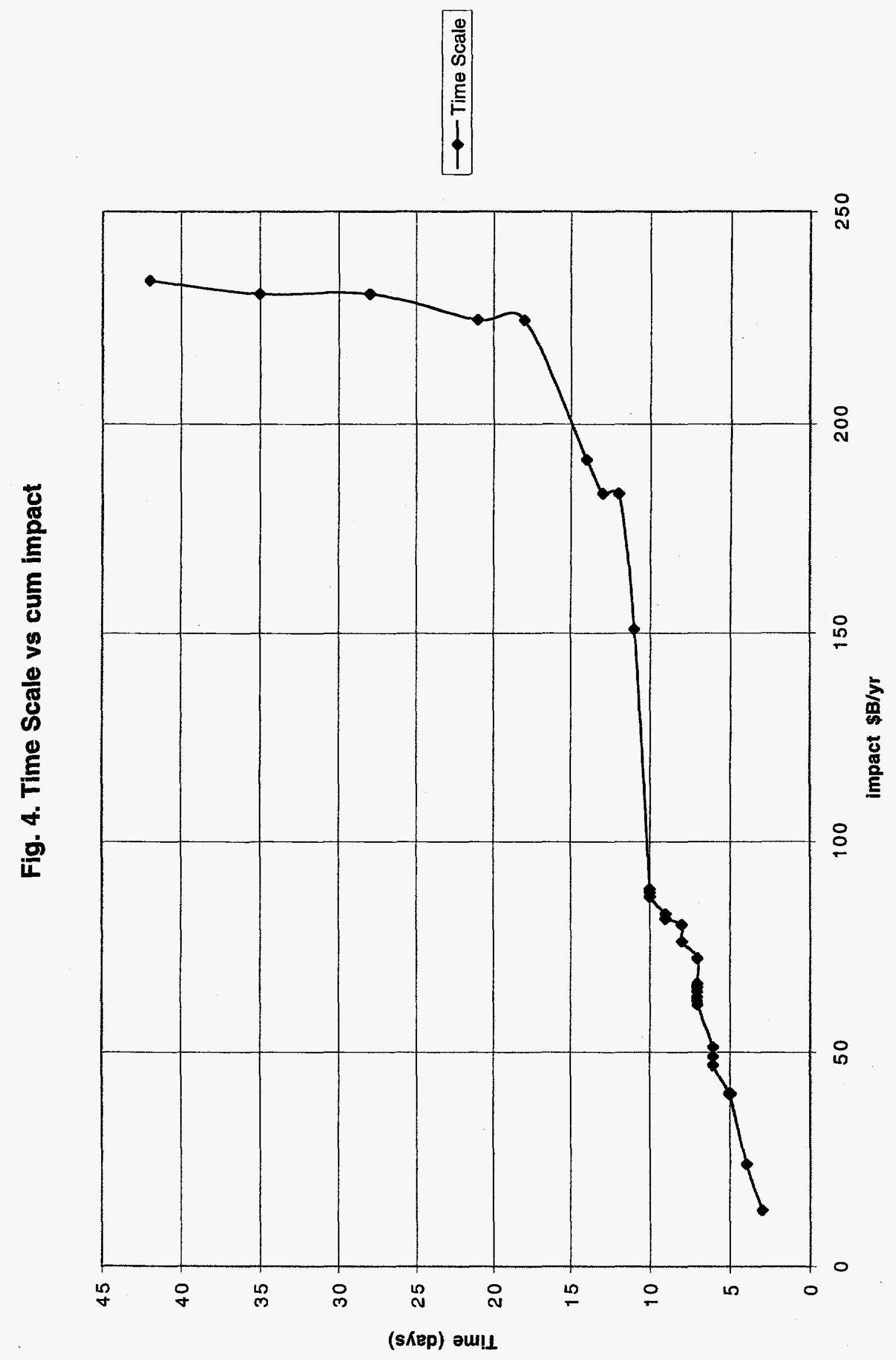




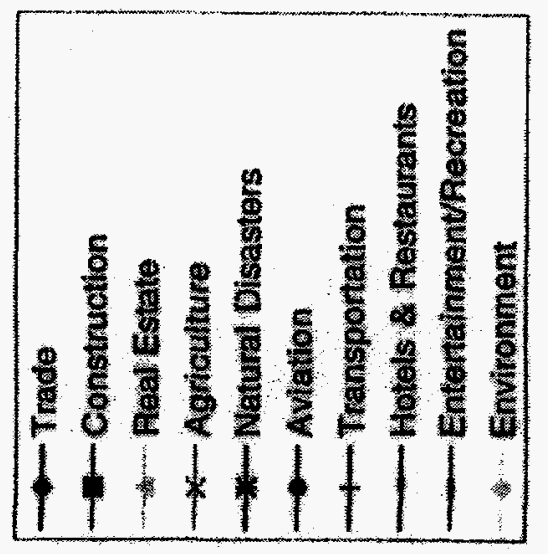

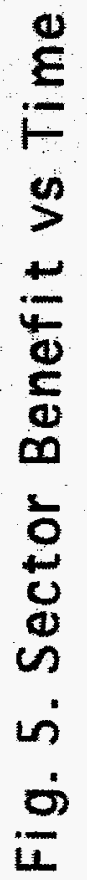

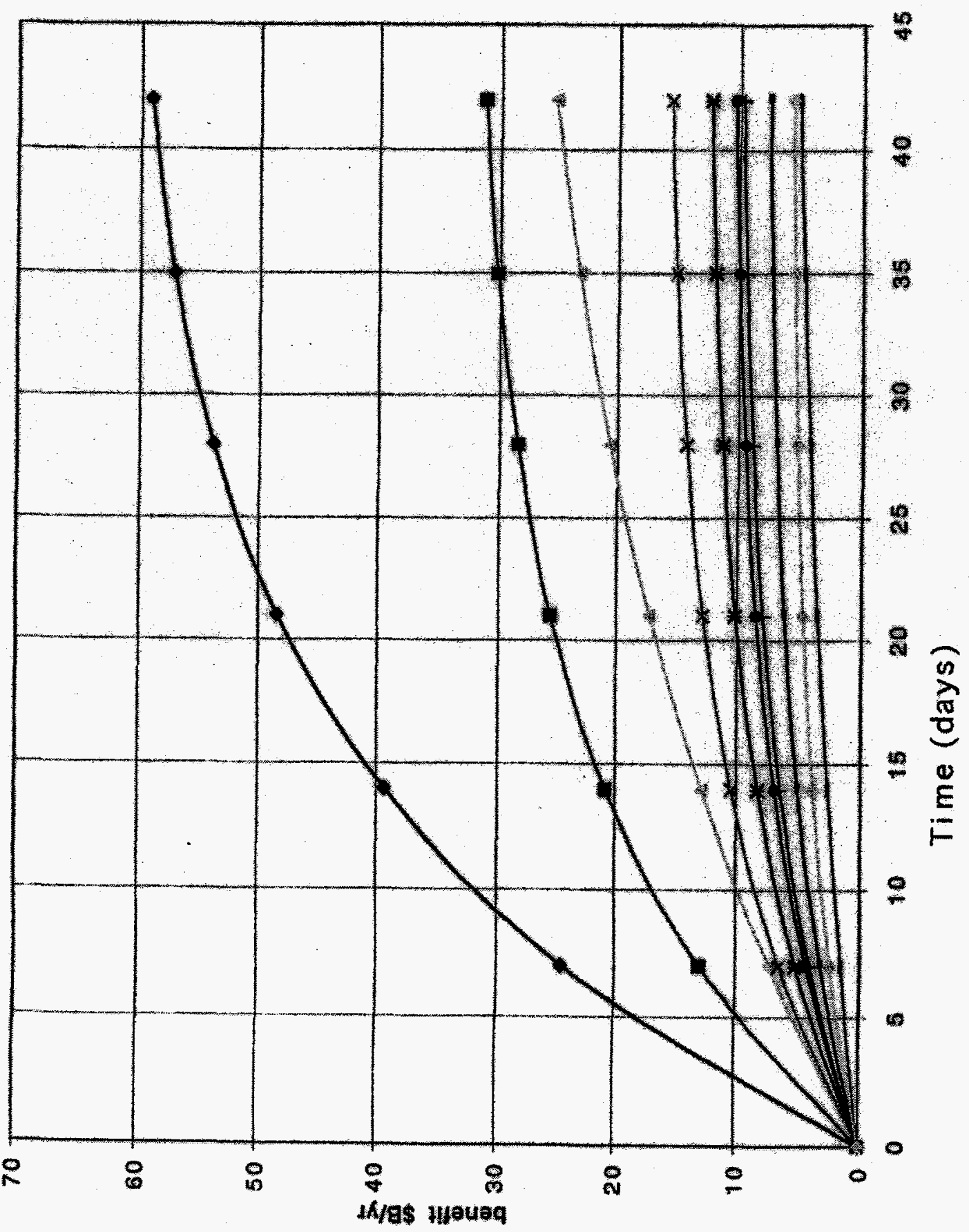




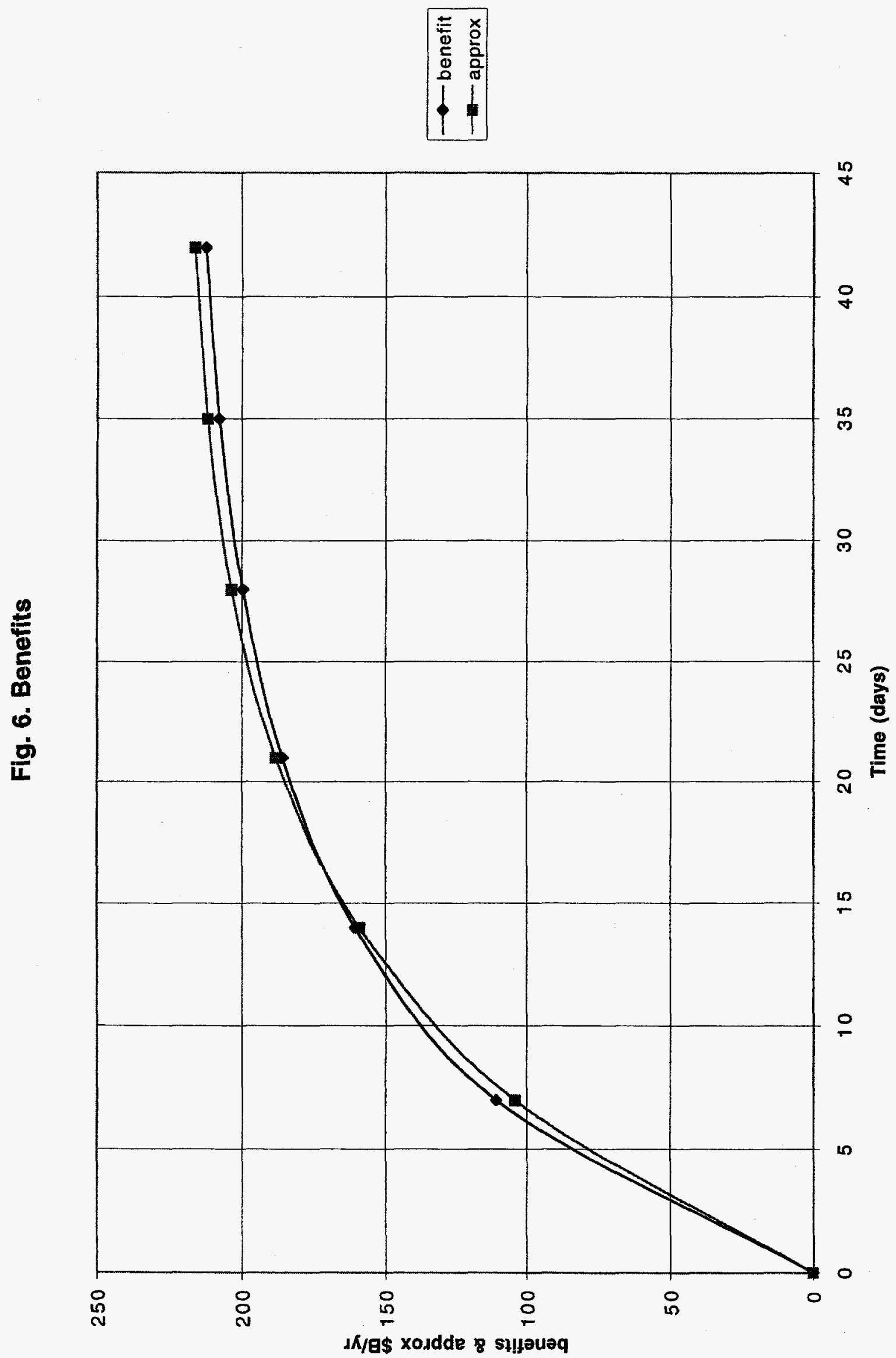

